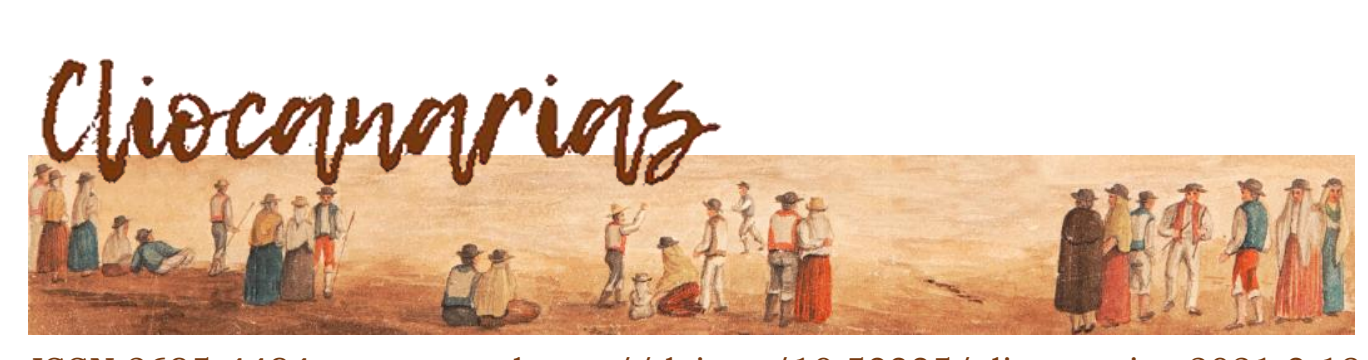

ISSN 2695-4494

https://doi.org/10.53335/cliocanarias.2021.3.18

\title{
ENTREVISTA A MANUEL DE PAZ SÁNCHEZ*
}

INTERVIEW WITH MANUEL DE PAZ SÁNCHEZ

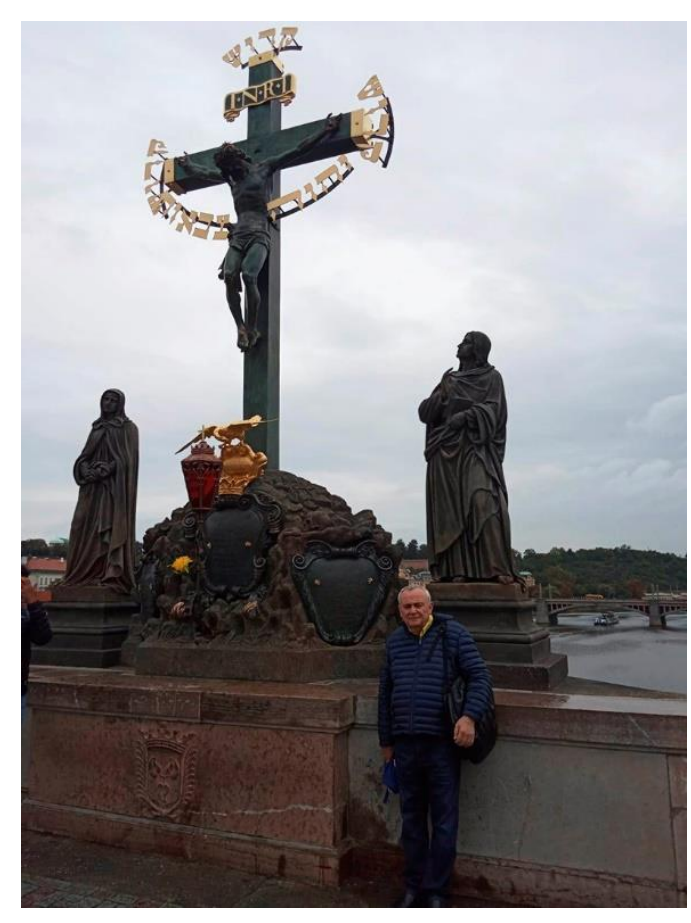

El historiador elegido para dialogar en este tercer número de la revista es Manuel de Paz Sánchez, catedrático de Historia de América de la Universidad de La Laguna, cuyas aportaciones a la historia (del archipiélago y de América) son extraordinarias en cantidad y calidad, abarcando facetas diversas como investigador, fundador-director de una renombrada colección de libros de historia, director de casi una decena de tesis doctorales, etc.

CLIOCANARIAS: Su pasión por la investigación histórica le comenzó muy pronto, pues ya durante sus estudios universitarios estaba recopilando información para algunos temas, en especial para el que sería durante los años siguientes su principal centro de atención: la masonería. ¿Cómo principió esa dedicación? ¿Hubo algún acontecimiento, experiencia o persona que lo impulsara o animara?

MANUEL DE PAZ SÁNCHEZ: Creo que hay un factor determinante: mi condición de hijo de La Palma. En la isla y, en especial, en Santa Cruz de La Palma, donde nací y me crie, la masonería siempre estuvo rodeada de un halo particular, no solo de misterio como es fácil suponer, sino de una serie de peculiaridades que la hacian especialmente interesante. Generalmente sus miembros eran muy solidarios, muy fraternos, se mantuvieron unidos a pesar de las dificultades y, en conexión con el resto de Canarias y de España, desarrollaron actividades interesantes, especialmente en el ámbito de la beneficencia, y gozaron de contactos y relaciones en la esfera internacional, sobre todo con América. También fueron un núcleo político-cultural de referencia

* Catedrático de Historia de América. C. e.: mdpaz@ull.es 
en la isla como, con figuras señeras como Manuel Diaz, y con una serie de personajes que tuvieron una notable importancia tanto en Canarias como en el exterior. Pensemos por ejemplo en don Alonso Pérez Diaz, en Diógenes Diaz Cabrera, que siempre mantuvo muy viva la fe en los ideales masónicos, en numerosos elementos del ámbito político, educativo, científico, cultural. Creo que la masonería palmera representó muy bien algunos de los elementos definitorios del ideal racionalista, democrático y solidario propio de la orden. Por otro lado, el hallazgo de la documentación de las logias insulares en Salamanca (en el actual Centro Documental de la Memoria Histórica), me permitió realizar una investigación tanto de La Palma como del resto de Canarias, cuya dimensión internacional resulta muy interesante bajo distintos puntos de vista.

C.: Usted creó y dirigió la colección de libros Taller de historia, una empresa compleja (50 títulos y unos 52 autores) que, con la ayuda de una institución cultural y la de diversas administraciones, era novedosa en las islas y constituye un referente historiográfico. ¿Qué balance puede hacer de ese repertorio de investigaciones? ¿Hay posibilidades de continuar con esas publicaciones? En caso de tener oportunidad, ¿qué aspectos, épocas, temas o autores le gustaría incorporar a esa selección?

M. P. S.: Fue un proyecto especialmente querido. Se contó con la colaboración de numerosas instituciones, sobre todo del archipiélago, que permitió publicar todos esos libros, con tiradas realmente interesantes para obras de tipo académico. Las ediciones se difundian bastante, de acuerdo con el aparato logístico del Centro de la Cultura Popular Canaria, que distribuía muy bien. La idea inicial fue poner en valor, dentro y fuera de Canarias, la labor investigadora y la calidad de las investigaciones generadas por universitarios del archipiélago (no solamente sobre historia regional, sino en general), y, en algún que otro caso, por colegas del exterior, especialmente del Consejo Superior de Investigaciones Cientificas, aunque en mucha menor cantidad y siempre en relación con temas vinculados a las islas y a su influencia exterior (presencia canaria en Cuba, Venezuela, viajeros, etc.). Fue un reto, sobre todo en la época "pretelemática", con las dificultades inherentes a la distribución de los libros por la distancia geográfica con las grandes capitales europeas y americanas. Se hizo, por autores y técnicos, un esfuerzo enorme. La gente acogió bien el proyecto, y conté con entusiastas compañeros de viaje, como el profesor Manuel Hernández, Consuelo Naranjo, José Juan Batista y otros muchos que, a pesar de no nombrarlos aqui, están muy presentes en cuanto a la relevancia y a la repercusión de Taller de Historia.

La línea de investigación sobre relaciones internacionales, no ya de Canarias, sino de España y Cuba en los primeros tiempos tras el triunfo de la revolución cubana fue, asimismo, otra línea de trabajo sobre la que, recientemente, se ha leído también una tesis doctoral en la Universidad de La Laguna. Un tema apasionante que conecta, desde las propias vísperas del proceso revolucionario, a Cuba y Venezuela.

Respecto al futuro, la verdad es que me gustaría que Taller de Historia tuviera una segunda etapa, pero creo que la época de las grandes tiradas de libros académicos (a partir de 2.000 ejemplares) pertenece al pasado. Ahora 
se impone la edición digital, la difusión masiva a través de internet y las tiradas cortas o muy cortas en papel. Y, en relación con los temas, personalmente me hubiese gustado continuar con la línea que, en la etapa final de la colección, contó con algunos títulos emblemáticos en relación con las descripciones y memorias de viajes. La mirada del viajero sobre Canarias, que siempre nos enriqueció y nos permite analizarnos a través de la alteridad; el interés científico del Archipiélago: geográfico, geológico, botánico... También, en el ámbito de las relaciones internacionales, nuestros vínculos históricos con América y, asimismo, con el Norte de África y con Europa. Todo esto y otros muchos temas que sería prolijo detallar, pero que se encuadran en las líneas de investigación más recientes, a escala global, de acuerdo con los avances y los intereses histórico-culturales de la metodología histórica.

Actualmente codirijo dos colecciones en Ediciones Idea, "Cuadernos del Magreb" y "Escuadra y compás". La primera de temas centrados en el Norte de África, donde cada vez se pretende dar más cabida a los trabajos de tipo histórico. La segunda se ocupa de historia de la masonería, tanto en su dimensión regional como estatal e internacional.

C.: Desde su experiencia ya larga en el mundo de la investigación (más de cuatro décadas), la coordinación de obras colectivas, la dirección de ocho tesis doctorales, la ya comentada creación de Taller de historia... ¿Puede mencionar períodos o temas de la historia de Canarias que le gustaría ver más analizados y publicados? ¿Entiende que es indispensable una renovación metodológica en la historiografia canaria, una búsqueda de otros enfoques, acaso más investigación de equipo... o quizá se sobrevalora el seguimiento de nuevas corrientes o tendencias historiográficas?

M. P. S.: ¿Tanto tiempo ha pasado? (Es broma). Pero, en realidad, son nueve tesis doctorales hasta septiembre del 2020. No creo que se sobrevalore el seguimiento de nuevas corrientes o tendencias. Es una obligación de las humanidades, lo mismo que de cualquier otra actividad científica y académica, modernizarse y ello solo puede hacerse equivocándose, explorando nuevas vías, analizando nuevos temas, reparando en nuevos enfoques, explorando nuevos ríos en esta inmensa selva del conocimiento científico. Anquilosarse en métodos más o menos tradicionales es algo en lo que nunca debe caer un buen investigador. Viera ofrece, ya desde su tiempo, algunos consejos muy útiles que perviven a lo largo del tiempo.

Hay que renovarse, a pesar de que podamos equivocarnos, pero ello nos obligará a buscar caminos alternativos. Tampoco es recomendable caer en la autocomplacencia, porque, en el fondo, todos somos conscientes de que cualquier obra, por exhaustiva que sea, cualquier trabajo puede o pudo hacerse mejor. Es la sensación que muchos autores confesamos haber tenido cuando se termina un libro. No sé. Ni resignarse ni conformarse nunca, algo así.

C.: Ha dedicado un notorio esfuerzo a la reedición de una serie de obras de Viera y Clavijo, del libro de Bernardino de Riberol de mediados del s. XVI, así como al análisis muy documentado sobre el corsario Amaro Pargo. ¿Son oportunas estas reediciones? ¿Qué otros autores o tratados clásicos de la historia de Canarias merecen más atención y quizá podrían ser reeditados y actualiza- 
dos con las anotaciones pertinentes? ¿Podría señalar qué biografias de personajes fundamentales en la historia canaria deben ser estudiadas a corto plazo? ¿Resulta realmente indispensable el acompañamiento de un amplio repertorio documental?

M. P. S.: Esta pregunta hubiese hecho feliz a algunos historiadores, especialmente a los que se preocupan por buscar nuevas pautas metodológicas. ¡Cuatro en una! Bueno, empecemos por el principio. La edición del libro de Bernardino de Riberol, Libro contra la ambición desordenada de aqueste tiempo: llamado alabanza de la pobreza (1556), el primer libro que vio impreso un autor canario, fue una experiencia profesional llena de retos y satisfacciones, como la constatación definitiva de las influencias de Erasmo de Rotterdam en el autor isleño. Surgió en conexión con otro trabajo en tres volúmenes, Flandes y Canarias: nuestros orígenes nórdicos, en el que participaron numerosos autores de las dos universidades canarias. La inmersión en el Renacimiento canario, bajo el signo de la colonización de las islas realengas, fue una experiencia de la que guardo recuerdos entrañables, especialmente porque se consiguió reunir a un plantel de autores de todas las islas. Es un proyecto en el que me hubiese gustado insistir para algunos temas, tanto de la etapa moderna como contemporánea, y, naturalmente, tanto de Canarias, en sí misma, como de sus interinfluencias con el exterior. Son temas apasionantes que nunca se agotarán.

Respecto a la edición crítica de algunas obras del polígrafo José de Viera y Clavijo (1731-1813), me siento muy feliz de haber realizado tres estudios criticos de algunas de sus obras más representativas, concretamente en el ámbito de la Historia y de la historia cultural: su Historia de Canarias, El Hieroteo y Reales Academias. Respecto a la primera, a tiempo pasado, la verdad es que creo que no volvería a hacerla si me lo volvieran a ofrecer desde Ediciones Idea, pues constituyó un enorme sacrificio personal. Estuve cuatro años trabajando, todos los días, en esta edición. Al final me llevé algunas alegrias, al descubrir, por ejemplo, las diferencias entre los capítulos conservados de la "versión original" y la edición príncipe, las tablas sobre las fuentes de la Historia, el incremento de "bárbaros" entre el original y la primera edición, la escasez de vocablos

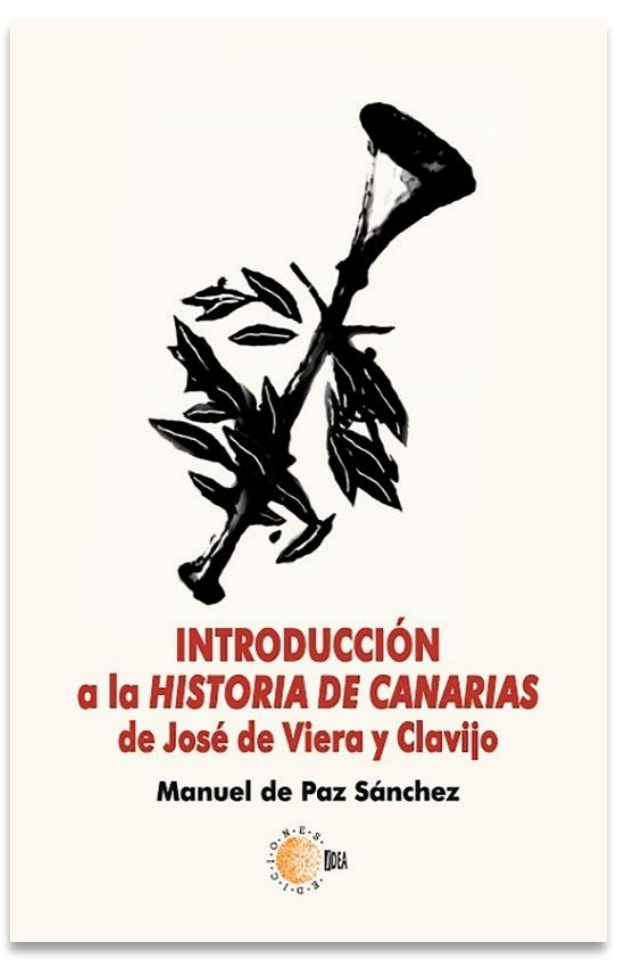
laudatorios de los conquistadores en el citado original respecto a lo que salió impreso. Sin olvidar el tema evolucionista y el concepto de degeneración en boga durante la época de Viera. Y, luego, cantidad de notas eruditas sobre los más diversos asuntos.

Amaro Rodríguez Felipe, Amaro Pargo, es un personaje muy representativo de Canarias y, en especial, de Tenerife durante la primera mitad del siglo 
XVIII, cuando la isla se convirtió no solo en un destacado enclave defensivo, sino, particularmente, ofensivo. Las actividades corsarias fueron especialmente notorias. El personaje estaba rodeado de numerosas leyendas y anécdotas que se hacía necesario desbrozar, de ahí que, en colaboración con un equipo de investigadoras e investigadores, estemos publicando toda esa masa documental, que creo que es muy importante para colocar la verdad histórica en su lugar y, asimismo, para ofrecer nuevas líneas de investigación y de análisis en relación con este importante capítulo de nuestra historia atlántica.

C.: En su producción historiográfica americanista se ha consagrado en especial al área caribeña, con preferencia por la Cuba contemporánea. ¿Piensa continuar investigando el acontecer relativamente reciente de ese país o de otros del ámbito americano? Dada la relación estrecha con esta cuestión y por tratarse de un fenómeno actual, al que le ha dedicado en los últimos tiempos una cierta atención: la "estatuafobia", ¿puede recordar, en sintesis, su opinión al respecto?

M. P. S.: El área del Caribe y Cuba, en particular, ocupa un lugar esencial en las relaciones entre Canarias y América. Como le dijo Fernando Ortiz a Luis Felipe Gómez Wangüemert cuando éste le interrogó acerca del escaso interés que, en principio, otorgaba Ortiz al papel de los canarios en Cuba: es que son casi cubanos. Desde luego, fue una salida diplomática, pero es representativa. Para el caso de Cuba, sobre todo, he tratado de estudiar temas como el bandolerismo social, de acuerdo con el modelo de Eric J. Hobsbawm, con quien tuve la oportunidad de cartearme y recibí algunos de sus sabios consejos, y, por otro lado, también he trabajado algunos temas en relación con la masonería, incluso algún estudio comparativo entre Cuba y Marruecos. Es una linea de investigación relativamente reciente y muy prometedora, sobre la que se acaba de leer justamente el año pasado, para el caso concreto del protectorado de Marruecos, una tesis doctoral que codirigí, junto con José Antonio Piqueras, en la Universidad Jaume I de Castellón.

El tema del derribo de estatuas de Colón y de otros personajes históricos daría para un libro. Es como si un sector de la población se enfrentase al pasado desde el presente, como queriendo borrar la historia que es la que es, con sus luces y sus sombras. Esto es así desde el principio de los tiempos, obviamente. A veces tengo la impresión de que es una reacción irracional ante la "imposibilidad" de cambiar el presente, que es lo que toca, ya que la historia no la podemos cambiar, como mucho ofrecer imágenes más o menos distorsionadas, calidoscópicas también, sobre los hechos, que son los que son, por mucho que nos duelan. Creo que se exagera en este asunto, al calor de determinados temas de actualidad, que son actos de desesperación. Navegamos un poco también, en estos tiempos que corren, hacia el corazón de las tinieblas. ¿No es contradictorio que el siglo XVIII, en el que surge la democracia y la ciudadanía en términos contemporáneos, en cuanto a fuente de derechos, fuera, precisamente, el que mayor número de esclavos hizo cruzar el Atlántico con destino a las plantaciones americanas o, lo que es lo mismo, muchas veces hacia una muerte segura? ¿Qué clase de civilización puede hacer esto? Pero los hechos están ahí, y el dolor sobrevive en la memoria, 
junto con las conquistas y los logros de los "gigantes" y no tan gigantes que nos precedieron.

C.: En su extenso currículo de publicaciones no solo las hay de historia. También ha realizado incursiones con un sesgo filosófico y algún libro de poemas. ¿Podría adelantar algún propósito, idea o proyecto editorial pendiente que piense emprender en los próximos años?

M. P. S.: Estamos trabajando en diversos asuntos. Algunos recurrentes: el de la historia de la francmasoneria, por ejemplo. Pero también otros temas como los relativos a la esclavitud y al abolicionismo, aspectos de historia cultural, la figura de Amaro Pargo, etc. Desde el punto de vista del ensayo literario o la creación, sin embargo, la producción es poco representativa, más bien de indole personal, es decir, de temas que te pueden gustar, pero que no es lo tuyo. Mi oficio es el de historiador. No tengo otro.

C.: No se han prodigado los historiadores del archipiélago en el último siglo en elaborar historias generales de Canarias en profundidad, abarcando varios volúmenes: ¿ha llegado el momento de plantearse una tarea de esa naturaleza? ¿Estima que debe ser una labor singular, individual, un equipo reducido o un amplio conjunto de historiadores? ¿Qué características serian recomendables en un trabajo de esa enjundia? Por último, ¿cómo podría mejorar la disociación que a veces se observa entre la producción historiográfica y el conocimiento popular, incluyendo la inadecuación entre el saber historiográfico y el transmitido en los centros de enseñanza?

M. P. S.: Yo creo que las historias generales son una cosa del pasado, como decía antes de las grandes tiradas de libros académicos en papel. La riqueza de la historia es tan inmensa como la vida misma, evoluciona, se transforma, se adapta, sobrevive... Escribimos de lo que somos. Ello no quiere decir que no dediquemos más esfuerzos a divulgar el verdadero conocimiento histórico, pero se acabará haciendo por decantación, sobre todo en esta época en la que se divulgan tantos errores y dislates a través de Internet. He leído disparates sobre Amaro Pargo y la Siervita Sor María de Jesús, por ejemplo, que no hubiese escrito ni José Rodríguez Moure a principios del pasado siglo, que escribió bastantes al respecto.

Por todo ello, en relación con el saber y las visiones populares sobre determinados episodios históricos, la situación es bastante compleja. Es un fenómeno antropológico. Como en cualquier investigación científica, nuestro deber es suministrar, con el máximo rigor y de la mejor manera posible, conocimiento histórico contrastado, veraz, riguroso, seguro. Todo lo que se haga en este sentido contribuirá, más temprano que tarde, a poner la verdad en su lugar, a enriquecer nuestra visión de las cosas, de la vida; a mejorar la confianza y a aumentar las redes de solidaridad en esta sociedad cada día más global y, por una de esas contradicciones históricas, cada día más individualista. No hay otra opción.

C.: Muchas gracias. 